\title{
Effects of some insecticides on longevity of the foragers honey bee worker of local honey bee race Apis mellifera jemenatica
}

Dalal Musleh Aljedani, Roqaya Mohammed Almehmadi

Department of Biology, Faculty of Sciences, AL Faisaliah Campus, King Abdul Aziz University, Jeddah, Saudi Arabia

\section{Type of article: Original}

\begin{abstract}
Introduction: Honeybees are constantly exposed to a wide range of vital and non-vital pressures that may interact with each other and affect the health or survival of the insects. Pesticides are the main danger for the insects, and they subsequently have impacts on human and environmental health.

Methods: Field research was conducted in the apiary of Hada Al Sham Research Station, where the worker honeybees forager Apis mellifera jemenatica were selected to examine the effect of pesticides on workers' longevity. We used three insecticides, i.e., deltamethrin, malathion, and abamectin, in different concentrations. The longevity of worker honeybee foragers was calculated; the honeybees were supplied with water, food, natural protein, and sugar solution laced with selected insecticide by mouth under laboratory conditions.

Results: The longest period of insect longevity was 15.5 days when using deltamethrin concentrate at a concentration of $1.00 \mathrm{ppm}$; the lowest longevity was two days when using abamectin at a concentration 1.00 $\mathrm{ppm}$. The longevity of the unexposed forager worker honeybees was 18 days, as the variation in the intensity of the effect of the insecticide on the bees appeared with the severity of the effect diminishing in the order of abamectin followed by malathion followed by deltamethrin.

Conclusion: The study found that the type and concentration of the insecticides that are found in the honeybees' food had a significant impact on the time of survival of the insects. The longevity of a worker honeybee depends on the health and safety of all of the members of the beehive, and safe alternatives to insecticides must be used because of the danger imposed by the application of insecticides on the continuity of life of the entire society depends on the life of this layer bee community.

Keywords: pesticides, longevity, worker honeybee foragers, Apis mellifera jemenatica
\end{abstract}

\section{Introduction}

The honey bee insect belongs to the order Hymenoptera of the Family Apidae of the Genus: Apis, subordinated by the western honey bee Apis mellifera jemenatica Ruttner that has spread out all around the Earth. It is in several geographical areas and spaced eras, and such isolation has resulted in a large number of strains of this type, including the Yemeni bee strain (domestic honey bees) Apis mellifera jemenatica, which is the prevalent strain in the Arabian Peninsula, both in Yemen and Oman as well as in Saudi Arabia, and it also has spread to some parts of Africa. Honey bees, like other living organisms, are exposed continuously to a wide range of biological and nonbiological pressures, such as environmental factors, which may interact with each other and affect the health or survival of the insects $(1,2)$. Many industrial substances are used to fight insect pests in agricultural areas, but the indiscriminate use of these substances affects non-targeted insects, such as bees (3). Many insecticides are used routinely to protect crops against insects to prevent economic losses (4). The literature pointed out that the harmful impact of deadly doses of different pesticides shows on the behavior of the insect during its return flight, and they affect the insects' sense of orientation and foraging efficacy (5). In spite of that, many scientific references have

\section{Corresponding author:}

Roqaya Mohammed Almehmadi, Department of Biology, Faculty of Sciences, AL Faisaliah Campus, King Abdul Aziz University, P.O. Box 19516 Jeddah 21445, Saudi Arabia.

Tel: +966504629210, Email: d_almehmadi@yahoo.com

Received: November 27, 2015, Accepted: January 03, 2016, Published: January 2016

iThenticate screening: December 29, 2015, English editing: January 05, 2016, Quality control: January 08, 2016

(C) 2015 The Authors. This is an open access article under the terms of the Creative Commons Attribution-NonCommercialNoDerivs License, which permits use and distribution in any medium, provided the original work is properly cited, the use is non-commercial and no modifications or adaptations are made. 
referred to the disappearance of honey bees in the 1880s, 1920s, and 1960s, and a description of what looked like a phenomenon of bee colonies Colony Collapse Disorder (CCD), the diagnosis of the causes of bee disappearance include disease, such as "paralysis, viruses, and nosemea (6), and environmental factors, such as global warming and monoculture (7), and pesticides, whether to combat the mites inside the bee hives or field pesticides (8), but there's no way to be sure of whether the factors causing the sudden death in those years are the same of those leading to this problem now concerning the sudden death of bees. Maybe the most different Stupendous and the most important event is the synchronization of this phenomenon all over the world (9) or the so-called phenomenon of honey bee depopulation syndrome (HBDS) (10). There is no single reason for their disappearance, but many scientists have implicated the poor sanitary environment for the bees inside or outside the hives as being one of the most important causes for the loss of bees $(11,12)$. The hives' hygiene is influenced with many factors, including hygienic management, innate immunity, viral illnesses, and their pesticide sensitivity, nutrition, adult age, and temperature $(11,12)$. Those stressful factors weaken the immune system of the bees just as it does with other social insects, and they may lead to disabling its social system, making them more susceptible to diseases. Several statistics have revealed high levels of pollution of honey bees' combs with pesticide residues, and this study was conducted to test the direct and indirect potential impacts, the length of life of adult honeybee workers. Honeybee workers were bred in the brood combs containing high levels of known pesticide residues, in addition to a control group of non-treated brood combs. It was observed in honey bees brought up in high levels of pesticides, especially in the early ages of 4 -8 days, delays in growth, and it also a decrease in the life of the adult honey bee workers was observed, at the rate of four days in bees exposed to such residues, as pesticide residues are transmitted from the combs containing high percentage of pesticide residues to the non-treated combs after cycles of ongoing broods, giving the effects of how fast is the transmission of the residues through honey bees wax, which supports the need to replace honey bee combs. The chemical analysis after conducting the experiment explained the migration of pesticide residues from the treated combs to the non-treated combs in advance. This study is the first of its kind to determine the less than deadly effects of the exposure of the foraging bee combs to pesticides. These effects include larva delayed growth, and full insect delayed hatching, and low longevity of the adult, and this may probably impose indirect effects on communities, such as early transformations in hive phases, and the activity of the foraging honeybee worker insects, in addition to lengthening the time of growth that could lead to the growth of the devastating parasite of Varroa mites. It is necessary to study the impact of the delayed growth of the honey bee population on the activity and fertility of this parasite (13). In 1994, beekeepers in France issued a report containing worrisome signs, i.e., many honey bees did not return to their hives; rather, they gathered in small groups nearby to each hive close to the ground or moving in a disturbed manner in front of the hives, and the foraging honey bee workers showed abnormal manifestations in behavior, where such signs were accompanied by losses in the winter season (14). In a study conducted by Karise et al. (15), it was found that kaolin is an inert material and has a wide range of applications; such as an insecticide, and as a substance may be added to fill iological pesticide compounds, thus, bumble bee workers are exposed to pesticides in the field and therefore are subjected to side effect risks of those pesticides. The study's results showed that treatment with pure kaolin only increases water loss in the ice layer, and reduces its resistance for survival, but when mixing kaolin with real fungi, would lead to a negative impact on the longevity of the bees. Due to the lack of ongoing research in the Kingdom of Saudi Arabia in serious study of the impact of insecticides on the life of honeybee insects, it necessitated the conduct of a biological study to determine the extent of the insecticides' effects under study, i.e., deltamethrin, malathion, and abamectin, on the longevity of the honey bee insect (foraging worker) at different concentrations when used orally.

\section{Material and Methods}

\subsection{Study setting}

The field research was conducted in the apiary of Hada Al Sham Research Station, which is a model station for agricultural research in the King Abdulaziz University (Saudi Arabia). The honeybees used in the study were Yemeni bee race (local)-Apis mellifera jemenatica-which have been subjected to research. It is one of the yellow bee strains spread in many parts of the Arabian Peninsula, distinctive of its adaptation under environmental conditions prevailing in Saudi Arabia, and its disease resistance (16). Individuals used in the study were the foraging honeybee workers, which are individuals working outside the hive in collecting nectar and pollen, but are characterized with being fed on the nectar or honey in larger amounts (carbohydrates nutrition). Foraging honeybee workers were chosen to conduct the study according to Oldroyd and Nanork (17) and Khoury et al. (18), where two methods were combined for the design of wooden cages for breeding, taking into account that the one face of the wooden box is covered with metal wire mesh, while the opposite face would be of glass, based on what was mentioned by Kakmand et al. (19), and for holding cage measurements, were $(40 \times 30 \times 30 \mathrm{~cm})$. 


\subsection{Material and food administration}

The cage was provided, on the top side, with two plastic medical syringes $(50 \mathrm{ml})$, one of which with water, and the other syringe with sugar solution of $(1: 1)$ that is $(50 \%)$ (as a source of carbohydrates nutrition). $(50 \% \mathrm{w} / \mathrm{v})$ based on what was conducted by Bortolotti et al. (20), Medrzycki et al. (21), and Pohorecka (22), laced with insecticide solution under test. The cage was also provided with a small plastic pot of $3 \mathrm{~cm}$ in diameter, and $1 \mathrm{~cm}$ in height, put in the cage bottom to provide natural protein nutrition, (pollen) mixed with sugar in equal parts; where 50 grams of pollen and 50 grams of powdered sugar as well as a little water were added to get a paste, and then 10 grams of the such paste are put in the plastic pot, covered with a transparent perforated plastic sheet to allow feeding of bees and protection of the paste from drying out and preventing the adhesion of such food particles bees during feeding, where food is changed every three days Hatjina et al. (23).

\subsection{Time period of experiment conductance}

Samples were followed up daily until the death of all individuals in the study.

\subsection{Insecticides and concentrations used}

The adverse effects caused by three types of insecticides, representing the most prevalent groups, available in abundance in the Saudi market, used in pest control, were studied, namely: Deltamethrin; a compound of Pyrethroid group, Malathion, from the Organophosphates pesticide group, and Abamectin pesticide, from the Avermectin group. The use of Deltamethrin pesticide in the following concentrations: $1.00,2.50,5.00$, and $10.00 \mathrm{ppm}$, while with the Malathion pesticide, the following concentrations were used: $1.250,3.125,6.25$, and $12.5 \mathrm{ppm}$. In case of the Abamectin pesticide, the following concentrations were used: $0.025,0.1,0.5$, and $1.00 \mathrm{ppm}$.

\subsection{Study groups division}

The research experiences were divided into four groups, namely: 1) a non-exposed control group, 2) an exposed group to Deltamethrin, with different concentrations, 3) an exposed group to Malathion, with different concentrations, and 4) an exposed group to Abamectin, with different concentrations.

\subsection{Study procedures}

The forager honey bee workers were selected for the study, as they are individuals working outside the hive in the collection of nectar and pollen, where they have been fed orally, where they were provided with water and natural protein nutrition, and sugar solution laced with insecticide in the required concentration. After initial tests, the appropriate concentrations of each pesticide were selected, as the insecticides used in the study (Deltamethrin, Malathion and Abamectin) were prepared in four different concentrations. The Deltamethrin pesticide was used in the following concentrations: $10,5,2.5$, and $1 \mathrm{ppm}$, while the Malathion pesticide was used in the following concentrations: $12.5,6.25,3.125$, and $1.25 \mathrm{ppm}$, while Abamectin pesticide has been used in the following concentrations: $1.00 \mathrm{ppm}, 0.5 \mathrm{ppm}, 0.1 \mathrm{ppm}$ and $0.025 \mathrm{ppm}$, while the control group was not treated with any kind of pesticides, and were fed naturally, with water, natural protein nutrition as well as sugar solution, free of any additives, were used. The samples were followed up, as a bee would be considered dead when it remains motionless for 10 seconds of the observation period, after moving it gently by a fine brush (24). The longevity of the foraging honeybee worker, staying alive after its exposure, was calculated by daily follow-up and comparing to the control group. The experiment was repeated three times using 15 insects in each time.

\subsection{Statistical analysis}

All results were subjected to various statistical analyses by IBM-SPSS software, version 22.

\section{Results}

The results showed the effect of using different concentrations of pesticides on honeybee foraging workers Apis mellifera jemenatica throughout the life of these workers, where they were fed on sugary solution laced with insecticide of different concentrations under laboratory conditions. It was found through the results obtained in the present study (Table 1) that when using Deltamethrin insecticide in the following concentrations: 10, 5, 2.5, and 1 ppm, the average longevities for the workers were 2.5, 11, 14.5, and 15.5 days, respectively. In the case of the Malathion insecticide, the concentrations used in the study were $12.5,6.25,3.125$, and $1.25 \mathrm{ppm}$, and the average longevity for the workers were 3.5, 4, 4 and 6.5 days, respectively. As for the Abamectin insecticide at the concentrations tested namely; $1,0.5,0.1$, and $0.025 \mathrm{ppm}$, the average longevities for the workers were $2,3,3.5$, and 5 days, respectively. Whereas the foraging honeybee workers that were not subjected to any kind of exposure (control group) the average period of evolution and life of the workers was 18 days. Our observations showed that 
the longevity of foraging honeybee workers exposed to tested insecticides were as follows: the average longevity occurred when we used Abamectin insecticide at a concentration of $1 \mathrm{ppm}$ (higher concentration), to two days, thus took a shorter time than the other tested individuals, followed by individuals fed on food laced with Deltamethrin insecticide at concentration $10 \mathrm{ppm}$ (higher concentration), amounting to 2.5 days. As for Abamectin insecticide at a concentration $0.5 \mathrm{ppm}$, longevity reached three days, where it was close to those exposed to the same insecticide at concentration $0.1 \mathrm{ppm}$ and was also equal to the individuals fed on the Malathion insecticide at a concentration of $12.5 \mathrm{ppm}$ (higher concentration). While at concentrations 3.125 and $6.250 \mathrm{ppm}$, reached up to 4 days. Whereas the average longevity of honeybee workers exposed to the Abamectin insecticide at concentration of $0.025 \mathrm{ppm}$ (the least concentration), reached 5 days, which is approximately the length of the life of the honeybee workers fed on food laced with the Malathion insecticide at the concentration $1.25 \mathrm{ppm}$ (the least concentration) where the length of the lives of the bee workers treated therewith reached 6.5 days, and the period of evolution and the life increased of the bee workers fed with food laced with Deltamethrin insecticide at following concentrations 5, 2.5, and $1 \mathrm{ppm}$ (the least concentration) until it reached up to $11,14.5$, and 15.5 days respectively, which is the longest period in regards of the effect of insecticide on longevity. The results also showed that the longest life was reached by the insects was 15.5 days on the use of Deltamethrin insecticide at concentration $1 \mathrm{ppm}$ (the least concentration), while the least life time was 2 days on the use of Abamectin insecticide at concentration $1.00 \mathrm{ppm}$. While the longevity of foraging honeybee workers fed on natural diet (control) under lab conditions reached 18 days. The differences between the longevity of honeybee workers fed on food laced with solutions at concentrations of various insecticides tested when statistically analyzed were apparent. Whereas the Malathion insecticide, at a lower concentration, coefficient of variation in longevity was $32.6 \%$, which is the highest value of variation recorded. Abamectin insecticide had the highest impact on longevity, even when using the least concentration thereof, followed by Malathion insecticide, while the Deltamethrin insecticide was of least effect; where the bee workers stayed alive for a longer time compared to other individuals tested in the current study. Hence, it is clear that the type and concentration of the insecticide the bee workers received had a significant impact on the evolution period and longevity and survival of the foraging bee workers. When the effect of different concentrations of insecticides under study, on average longevity of the foraging bee workers Apis mellifera after exposure to these insecticides were put in order, it was found to be Abemectin, Malathion, and Deltamethrin, respectively.

Table 1. Mean of the honey bee forager workers' longevity after exposure to different concentrations of Deltamethrin, Malathion, and Abemectin

\begin{tabular}{|l|l|l|l|l|}
\hline Insecticide & $\begin{array}{l}\text { Concentration } \\
(\mathrm{ppm})\end{array}$ & $\begin{array}{l}\text { Longevity } \\
\text { Mean }\end{array}$ & SD & $\begin{array}{l}\text { Coefficient of } \\
\text { Variation (\%) }\end{array}$ \\
\hline \multirow{5}{*}{ Deltamethrin } & 1.00 & 15.5 & 0.71 & 4.56 \\
\cline { 2 - 5 } & 2.50 & 14.5 & 2.12 & 14.6 \\
\cline { 2 - 5 } & 5.00 & 11.0 & 1.41 & 12.9 \\
\cline { 2 - 5 } & 10.0 & 2.5 & 0.71 & 28.3 \\
\hline Malathion & 1.250 & 6.5 & 2.12 & 32.6 \\
\cline { 2 - 5 } & 3.125 & 4 & 0.0 & 0.0 \\
\cline { 2 - 5 } & 6.250 & 4 & 0.0 & 0.0 \\
\cline { 2 - 5 } & 12.50 & 3.5 & 0.71 & 20.2 \\
\hline Cbamectin & 0.025 & 5 & 1.41 & 28.3 \\
\cline { 2 - 5 } & 0.1 & 3.5 & 0.71 & 20.2 \\
\cline { 2 - 5 } & 0.5 & 3 & 0.0 & 0.0 \\
\cline { 2 - 5 } & 1.00 & 2 & 0.0 & 0.0 \\
\hline
\end{tabular}

\section{Discussion and conclusions}

Among the negative effects of the use of insecticides, their impact on non-target organisms, such as useful insects, was defined as the main cause for the disappearance of pollinators of agricultural fields, especially in single-crop farming areas (25-27). The risk of insecticides is not limited to toxicity, but it also has indirect harm to the insect, such as low efficiency and short life. This is consistent with Rortais et al., (28) in that all classes and ages of honeybees are sensitive to pesticides. The results of the current study showed that the longest life of honeybee workers exposed to pesticides was when using Deltamethrin insecticide at the least concentration of $1 \mathrm{ppm}$, where it reached 15.5 days, compared to other individuals tested in the current study. The foraging honeybee workers fed on 
a natural diet (control) under laboratory conditions, remained for a period of longevity 18 days. Wu et al. (13) found that the honeybee workers that have been bred in the combs containing insecticide residues at high levels live to average age of 4 days less than those not exposed, and this is consistent with the results of the current study, whereas Vosscher et al. (29) found that the average longevity of honeybee workers after entering foraging stage was less than 8 days. While the Malathion insecticide has medium impact on the longevity among the insecticides used therein; as the average longevity of a honeybee worker when using higher concentration of $12.5 \mathrm{ppm}$ and the least concentration of $1.25 \mathrm{ppm}$, between 3.5 and 6.5 days, respectively. The results of this study agree with what Smirleet al. (30) and MacKenzie (31) suggested, that topical treatment for members of honeybee workers with under lethal concentrations of insecticides Diazinon or Malathion have resulted in decreases in the length of life. The results of the study also showed that the lowest length of life was when using Abamectin insecticide at the highest concentration; where it showed an impact on longevity even when using the lowest concentrations thereof, as it was two days at the concentration of $1 \mathrm{ppm}$ (the highest concentration), which is the lowest period of life. Bonmatin et al. (32) and Deseneux et al. (33) pointed out that low doses of insecticides used, have proven its impact on longevity and foraging in adult honeybees. The exposure to below lethal concentrations of the Carbaryl insecticide of (Family: Carbamate) have negative effects on honeybee longevity and activities of foraging. Studies indicated that the getting acquainted with the different effects of pesticides on pollinators is a source of particular concern in agricultural systems $(8,34-37)$. The low longevity of adult honeybee workers in foraging stage can lead to the younger honeybee workers to begin earlier in search for food, and in the long run, this behavior can affect the internal system of the activities of the hive, including the care of the brood, food processing and storage, care paid to the queen, and effectiveness of hygienic behavior and foraging, which, in turn, leads to a breach in the balance of this colony, which was pointed out by Thompson et al. (38). It can be said that the type and concentration of the insecticide, the bee workers have fed on, has a significant impact on the evolution and survival of the foraging bee workers. When putting into order the effect of different concentrations of pesticides under study, on average longevity of foraging honeybee workers, Apis mellifera after exposure to these pesticides, were found to be as follows: Abamectin, Malathion, and Deltamethrin. When referring to the results of the toxic effects and toxin residues of some insecticides on foraging honeybee worker, it was found that the rate of death of the bee workers exposed to Deltamethrin insecticide was higher and average residues inside its body were less. Whereas in Malathion insecticide, the rate of death of the bee workers exposed was less, while the average pesticide residues in their bodies were higher, after 24 hours of exposure (39). Also, when referring to the results of detection of pesticide residues in foraging honeybee workers using gas chromatographic analyses, it was found that the average residue of Malathion insecticide was more than the Deltamethrin insecticide residue inside the body of honeybee samples that were exposed to different concentrations (40); and this explains why the length of the life of foraging honeybee workers exposed to the Deltamethrin insecticide, where it may be the absence of the concentrations of residues of the Deltamethrin insecticide in the body of the insect that gave it a greater chance of survival for longer periods, but samples of honey bees exposed to the Malathion residues of this pesticide led to decreased longevity. The life of a honeybee worker and its longevity depend upon the health and safety of all of the members of the beehive, so it is necessary, when the application of insecticides to the continuity of life, to take into account, the gravity of the entire society depends on his life in this layer of the bee community.

\section{Acknowledgments:}

The authors appreciate the support provided for this study by King Abdul Aziz University.

\section{Conflict of Interest:}

There is no conflict of interest to be declared.

Authors' contributions:

Both authors contributed to this project and article equally. All authors read and approved the final manuscript.

\section{References}

1) Holmstrup M, Bindesbøl A-M, Oostingh GJ, Duschl A, Scheil V. Interactions between effects of environmental chemicals and natural stressors: a Review. Sci Total Environ. 2010; 408: 3746-62. doi: 10.1016/j.scitotenv.2009.10.067, PMID: 19922980.

2) Gonza'lez-Varo JP, Biesmeijer JC, Bommarco R, Potts SG, Schweiger O. Combined effects of global change pressures on animal-mediated pollination. Trends Ecol Evol. 2013; 28: 524-30. doi: 10.1016/j.tree.2013.05.008, PMID: 23746938. 
3) Rossi CA, Roat TC, Tavares DA, Cintra-Socolowski P, Malaspina O. Brain Morphophysiology of Africanized Bee Apis mellifera Exposed to Sublethal Doses of Imidacloprid. Arch Environ Contam Toxicol. Springer Science+Business Media New York. 2013. doi: 10.1007/s00244-013-9897-1.

4) Pettis JS, Delaplane KS. Coordinated responses to honey bee decline in the USA. Apidologie. 2010; 41(3): 256-63. doi: 10.1051/apido/2010013.

5) Colin ME, Bonmatin JM, Moineau I, Gaimon C, Brun S, Vermandere JP. A method to quantify and analyze the foraging activity of honey bees: Relevance to the sublethal effects induced by systemic insecticides. Arch Environ Contam Toxicol. 2004; 47: 387-95. doi: 10.1007/s00244-004-3052-y, PMID: 15386133 .

6) Cox-Foster DL, Con DL, Clan S, Holmes EC, Palacios G, Evans JD, et al. A metagenomic survey of microbes in honey bee colony collapse disorder. Science. 2007; 318(5848): 283-7. doi: 10.1126/science.1146498, PMID: 17823314.

7) Potts SG, Biesmeijer JC, Kremen C, Neumann P, Schweiger O, Kunin WE. (2010) Global pollinator declines: trends, impacts and drivers. Trends Ecol Evol. 2010; 25: 345-53. doi: 10.1016/j.tree.2010.01.007, PMID: 20188434.

8) Johnson BR. Division of labor in honeybees: form, function, and proximate mechanisms, Behav Ecol Sociobiol, 2010; 64: 305-16. doi: 10.1007/s00265-009-0874-7, PMID: 20119486, PMCID: PMC2810364.

9) Bernal J, Garrido-Bailón E, Del-Nozal MJ, González-Porto AV, Martín-Hernández R, Diego JC, et al. Overview of pesticide residues in stored pollen and their potential effect on bee colony (Apis mellifera) losses in Spain. J Econ Entomol. 2010; 103: 1964-71. doi: 10.1603/EC10235, PMID: 21309214.

10) Van Engelsdorp D, Evans JD, Saegerman C, Mullin C, Haubruge E, Nguyen BK, et al. Colony collapse disorder: a descriptive study. PLoS One. 2009; 4(8): e6481. doi: 10.1371/journal.pone.0006481, PMID: 19649264, PMCID: PMC2715894.

11) Antúnez K, D’Alessandro B, Corbella E, Zunino P. Detection of chronic bee paralysis virus and acute bee paralysis virus in Uruguayan honeybees. J Invertebr Pathol. 2005; 90(1): 69-72. doi: 10.1016/j.jip.2005.07.001, PMID: 16169006.

12) Mullin CA, Frazier M, Frazier JL, Ashcraft S, Simonds R, van Engelsdorp, et al. High levels of miticides and agrochemicals in North American apiaries: Implications for honey bee health, Plos One. 2010; 5(3): e9754. doi: 10.1371/journal.pone.0009754, PMID: 20333298, PMCID: PMC2841636.

13) Wu JY, Anelli CM, Sheppard WS. Sub-Lethal Effects of Pesticide Residues in Brood Comb on Worker Honey Bee (Apis mellifera) Development and Longevity, PLoS ONE. 2010; 6(2): e14720. doi: 10.1371/journal.pone.0014720, PMID: 21373182, PMCID: PMC3044129.

14) Maxim L, Sluijs J. Emerging lessons from ecosystems. Late lessons from early warnings: science, precaution, innovation. Luxembourg: Publications Office of the European Union, 2013: 369-94. doi: $10.2800 / 73322$

15) Karise R, Muljar R, Smagghe G, Kaart T, Kuusik A, Dreyersdorff G, et al. Sublethal effects of kaolin and the biopesticides Prestop-Mix and Botani Gard on metabolic rate, water loss and longevity in bumble bees (Bombus terrestris). J Pest Sci. doi: 10.1007/s10340-015-0649-z.

16) Al-ghamdi AA. The effect of pollen supplementary feeding on some activities of honeybee colonies during summer season in Riyadh, Saudi Arabia .Saudi J Biol Sci. 2002; 9(2): 85-94.

17) Oldroyd BP, Nanork P. Conservation of Asian honey bees. Apidologie. 2009; 40: 296-312. doi: 10.1051/apido/2009021.

18) Khoury DS, Myerscough MR, Barron AB. A Quantitative Model of Honey Bee Colony Population Dynamics. Plos One. 2011; 6(4): e18491. doi: 10.1371/journal.pone.0018491, PMID: 21533156, PMCID: PMC3078911.

19) Kakmand FA, Mahmoud TT, Amin AM. The Role of Three Insecticides in Disturbance The Midgut Tissue in Honeybee Apis mellifera L. Workers, Kurdistan 1st Conference on Biological Sciences. J Dohuk Univ, 2008;11(1): 144-51.

20) Bortolotti L, Montanari R, Marcelino J, Medrzycki P, Maini S, Porrini C. Effects of sub-lethal imidacloprid doses on the homing rate and foraging activity of honey bees. Bull Insectol. 2003; 56(1): 63-7.

21) Medrzycki P, Montanari R, Bortolotti L, Sabatini AG, Maini S, Porrini C. Effects of imidacloprid administered in sub-lethal doses on honey bee behaviour. Laboratory tests. Bull Insectol. 2003; 56(1): 5962.

22) Pohorecka K. Effect of standardized plant herb extracts on general condition of the honey bee (Apis mellifera L.). Bull Vet Inst Pulawy. 2004; 48: 415-9. 
23) Hatjina F, Papaethimiou C, Charistos L, Dogaroglu T, Bouga M, Emmanoull C, et al. Sublethal doses of imidacloprid decreased size of hypopharyngeal glands and respiratory rhythm of honeybees in vivo. Apidologie. INRA, DIB and Springer-Verlag France. 2013; 44(4): 467-80. doi: 10.1007/s13592-013-01994.

24) Laurino D, Manino A, Patetta A, Porporato M. Toxicity of neonicotinoid insecticides on different honey bee genotypes. Bull Insectol. 2013; 66(1): 119-26.

25) Fletcher M, Barnett L. Bee poisoning incidents in the United Kingdom. Bull Insectol. 2003; 56(1):141-5.

26) Devine GJ, Furlong MJ. Insecticide use: contexts and ecological consequences. Agr Hum Values. 2007; 24(3): 281-306. doi: 10.1007/s10460-007-9067-z.

27) Freitas BM, Imperatriz-Fonseca VL, Medina LM, Kleinert AMP, Galleto L. Diversity,threats and conservation of native bees in the Neotropics. Apidologie. 2009; 40(3): 332-46. doi: 10.1051/apido/2009012.

28) Rortais A, Arnold G, Halm MP, Touffet-Briens F. Modes of honeybees exposure to systemic insecticides: estimated amounts of contaminated pollen and nectar consumed by different categories of bees. Apidologie. 2005; 36(1): 71-83. doi: 10.1051/apido:2004071.

29) Vosscher PK, Dukas R. Survivorship of foraging honey bees. Insectes Sociaux. 1997; 44: 1-5. doi: $10.1007 / \mathrm{s} 000400050017$.

30) Smirle MJ, Winston ML, Woodward KL. Development of a sensitive bioassay for evaluating sublethal pesticide effects on the honey bee (Hymenoptera: Apidae). J Econ Entomol. 1984; 77: 63-7. doi: 10.1093/jee/77.1.63.

31) MacKenzie KE. The effect of sublethal pesticide exposure on temporal division of labour and longevity in the honey bee (Apis mellifera L.), MPM contribution, Simon Fraser University, Burnaby, BC, Canada. 1986

32) Bonmatin JM, Marchand PA, Cotte JF, Aajoud A, Casabianca H, Goutailler G, et al. Bees and systemic insecticides (imidacloprid, fipronil) in pollen: subnano-quantification by HPLC/MS/MS and GC/MS, Environmental fate and ecological effects of pesticides, Re, A.A.M.d. et al., editors, 2007; 827-834, 978-887830-473-4.

33) Deseneux N, Decourtye A, Delpeuch JM. The sub-lethal effects of pesticides on beneficial arthropods, Annu Rev Entomol . 2007; 52: 81-106. doi: 10.1146/annurev.ento.52.110405.091440, PMID: 16842032.

34) Barnett EA, Charlton AJ, Fletcher MR. Incidents of bee poisoning with pesticides in the United Kingdom 1994-2003. Pest Manag Sci. 2007; 63(11): 1051-7. doi: 10.1002/ps.1444, PMID: 17918188.

35) Pinheiro JN, Freitas BM. Efeitos letais dos pesticidas agrícolas sobre polinizadores e perspectivas de manejo para os agroecossistemas brasileiros. Oecol Aust. 2010; 14(1): 266-81. doi: 10.4257/oeco.2010.1401.16.

36) Van Engelsdorp D, Meixner MD. A historical review of managed honey bee populations in Europe and the United States and the factors that may affect them. J Invertebr Pathol. 2009; 103 Suppl (1): 80-95. doi: 10.1016/j.jip. 2009.06.011

37) Blacquiere T, Smagghe G, Gestel CAMV, Mommaerts V. Neonicotinoids in bees: a review on concentrations, side-effects and risk assessment. Ecotoxicology. 2012; 21(4): 973-92. doi: 10.1007/s10646012-0863-x.

38) Thompson HM, Wilkins S, Batterby AH, Waite RJ, Wilkinson D. Modelling long-term effects of IGRs on honey bee colonies. Pest Manag Sci. 2007; 63: 1081-4. doi: 10.1002/ps.1457, PMID: 17879960.

39) Aljedani DM, Almehmadi RM. Toxicity effects of Some Insecticides on the Foragers Honey bee Worker of Local Honey bee race (Apis mellifera jemenatica). Saudi J Biol Sci. 2014; 20(5).

40) Aljedani DM, Almehmadi RM. Deltamethrin and Malathion insecticides residues in workers honeybees (Apis mellifera) and its relationship to these insecticides concentrations. 2015; 26(2). 